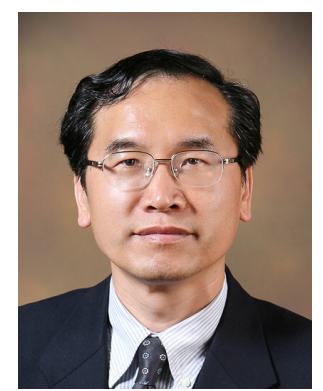

Received: January 1, 2020

Accepted: January 6, 2020

Correspondence author:

Soonhak Kwon, MD

Department of Pediatrics,

Kyungpook National

University Children's Hospital,

School of Medicine,

Kyungpook National

University, 807 Hoguk-ro,

Buk-gu, Daegu 41404, Korea

Tel: +82-53-200-2168

Fax: +82-53-200-2029

E-mail: shkwon@knu.ac.kr

\section{Celebrating 1st Birthday: Reborn into Eternity}

\author{
Soonhak Kwon, MD \\ Editor-in-Chief, Annals of Child Neurology \\ Department of Pediatrics, Kyungpook National University Children's Hospital, School of Medicine, \\ Kyungpook National University, Daegu, Korea
}

We are very delighted to celebrate the first anniversary of Annals of Child Neurology with you, our readers. I personally consider 2019 as the year of creative destruction for us. It was the year that we made a tremendous change in the scope of the journal, from the Journal of the Korean Child Neurology Society rooted since 1993 into an international, open access journal called Annals of Child Neurology. Despite the overwhelming worry Annals of Child Neurology has experienced a fairly long, but successful journey over the past year. We have published four issues and 25 articles covering a wide range of topics, such as epilepsy, genetic, infectious, inflammatory, and other neurological conditions. We made it!

I would like to express my sincere thanks to the distinguished members of our editorial board and our colleagues who serve as reviewers for their hard work. The members of our editorial board have given their priceless time to advise us to step forward. Our reviewers provided timely, objective and scientific evaluation necessary to accept or reject papers for publication. They have been able to choose the most valuable manuscripts based on the quality and the significance of study. Thanks are also due to the staff at M2 community and InfoLumi for their superb support. Without their dedication, Annals of Child Neurology simply could not survive. I am positive that Annals of Child Neurology will gradually get over the potential weakness by setting up a few fundamental frameworks such as a proficiently functioning scheme for processing manuscripts, a prestigious editorial board and reviewers with cool heads but warm hearts. Annals of Child Neurology will make new ways to 'never-thought-before' world in near future and the reader will find it practical and useful.

As always, we welcome and encourage constructive feedback and commentaries. Lastly, we hope you will celebrate with us at Annals of Child Neurology and visit us frequently at our web site, www.annchildneurol.org.

Best wishes and thank you in advance for your contribution to Annals of Child Neurology.

\section{Conflicts of interest}

No potential conflicts of interest relevant to this article was reported.

\section{ORCID}

Soonhak Kwon, https://orcid.org/0000-0002-0783-2243 